\section{Anaesthesia Management of a 6-year Child with Leigh Syndrome undergoing Stra- bismus Surgery}

Sir,

Leigh syndrome (LS) is an extremely rare neurodegenerative disease with multi-organ involvement; and is associated with genetic abnormalities, which affect mitochondrial enzymes. Neurological features in the patients may include hypotonia, ataxia, nystagmus, choreoathetosis, hyperventilation, apnoeic seizures, and peripheral neuropathy ${ }^{1,2}$ followed by central hypoventilation. $^{3}$

We report a case of a six-year female, a known case of LS and epilepsy, who was planned to have strabismus surgery. MRI brain showed symmetrical small areas of high signal intensity in posterior pons, dentate nuclei, thalami, periaqueductal area seen on $\mathrm{T} 2$ and dark signal intensity on T1-weighted images. Laboratory investigations showed raised pyruvate level as $101 \mu \mathrm{mol} / \mathrm{L}$ (Normal: $30-80 \mu \mathrm{mol} / \mathrm{L}$ ) and serum alanine level as $1090 \mu \mathrm{mol} / \mathrm{L}$ (Normal: 120-720 $\mu \mathrm{mol} / \mathrm{L}$ ), suggesting pyruvate dehydrogenase deficiency; and hence, resulting in primary lactic acidosis (Lactate: $6.28 \mathrm{mmol} / \mathrm{L}$ ).

Preoperatively, anaesthesia machine was prepared as vapourfree, according to recommendations by manufacturer in order to avoid the risk of malignant hyperthermia (MH). Patient received premedication with intravenous (IV) midazolam $1 \mathrm{mg}$ in preoperative area of operation theatre. Preoperatively, vital signs included heart rate of 85 beats/minute, blood pressure of $90 / 55 \mathrm{mmHg}$, oxygen saturation of $99 \%$ on room air and temperature $36.8^{\circ} \mathrm{C}$. Patient was pre-oxygenated with $100 \%$ oxygen via facemask, followed by induction with IV propofol $20 \mathrm{mg}$ and remifentanil as infusion at $0.05 \mu \mathrm{g} / \mathrm{kg} / \mathrm{minute}$. Muscle relaxant was not used. We then intubated the patient with size 4.5 RAE (Ring, Adair and Elwyn) cuffed endotracheal tube using conventional laryngoscopy. Anaesthesia was maintained using TIVA (Total intravenous anaesthesia) with propofol at $100-125 \mu \mathrm{g} / \mathrm{kg} /$ minute and remifentanil at $0.05 \mu \mathrm{g} / \mathrm{kg} / \mathrm{minute}$. Apart from one episode of bradycardia, patient remained haemodynamically stable during the whole procedure. We used $5 \%$ dextrose with $1 / 2$ strength saline at rate of $20 \mathrm{ml} /$ hour as maintenance fluid. At the end of operation, patient was extubated and transferred to recovery room, where she remained haemodynamically stable. She was kept in the ward for one day and later discharged from hospital.

As these patients have increased airway reactivity, so their respiratory functions should be optimised preoperatively. The presence of hypotonia and spasticity in these patients requires a cautious approach, while using opioids and muscle relaxants. ${ }^{1}$ The choice of anaesthesia induction agent in these patients has important implications. There are anecdotal reports of safety of volatile agents in LS patients, ${ }^{4}$ but there have also been some concerns regarding their potential to alter mitochondrial function and trigger $\mathrm{MH}^{5}$ There have also been concerns in the literature regarding use of propofol in these patients and risk of 'Propofol infusion syndrome, 'especially at higher dosage and duration. ${ }^{1} \mathrm{We}$ successfully used IV propofol and remifentanil in our patient for induction and maintenance of anaesthesia. Muscle relaxants, like succinylcholine, seem to be associated with rhabdomyolysis in patients with muscle diseases; while non-depolarising muscle relaxants can result in prolonged recovery time. Wein our case did notuse muscle relaxants atall.

\section{CONFLICT OF INTEREST:}

Authors declared no conflict of interest.

\section{AUTHORS' CONTRIBUTION:}

MY: Conception of work, literature search, final approval.

AUH: Literature search, writing manuscript, revising the work, final approval.

\section{REFERENCES}

1. Gozal D, Goldin E, Shafran-Tikva S, Tal D, Wengrower D. Leigh syndrome: anaesthetic management in complicated endoscopic procedures. Paediatr Anaesth 2006; 16(1): 38-42. doi: 10.1111/j.1460-9592.2005.01678.x.

2. Kocamanoglu IS, Sarihasan E. Anaesthetic management of a paediatric patient with leigh syndrome. Braz J Anesthesiol 2013; 63(2):220-2. doi: 10.1016/j.bjane. 2012.06.005.

3. Cooper MA, Fox R. Anaesthesia for corrective spinal surgery in a patient with Leigh's disease. AnesthAnalg 2003; 97(5):1539-41. doi: 10.1213/01.ane.0000081787. 94275.de.

4. Morgan PG, Hoppel CL, Sedensky MM. Mitochondrial defects and anaesthetic sensitivity. Anesthesiology 2002; 96(5):1268-70. doi: 10.1097/00000542-200205000-00036.

5. Bains R, Moe MC, Larsen GA, Johnsen, JB, Vinje ML. Volatile anaesthetics depolarize neural mitochondria by inhibition of the electron transport chain. Acta Anaesthesiologica Scandinavica 2006; 50(5):572-9. doi:10.1111/ j.1399-6576. 2006.00988.x.

Anwar UI Huda and Mohammad Yasir

Department of Anesthesia, Security Forces Hospital, Riyadh, Saudi Arabia

Correspondence to: Dr. Anwar Ul Huda, Department of Anesthesia, Security Forces Hospital, Riyadh, Saudi Arabia E-mail: hudaanwar90@yahoo.com

Received: February 15, 2020; Revised: March 30, 2020; Accepted: April 25, 2020

DOI: https://doi.org/10.29271/jcpsp.2021.02.243 